\title{
Leveraging effects of triple bottom lines business model on the building and construction small and medium-sized enterprises' market performance
}

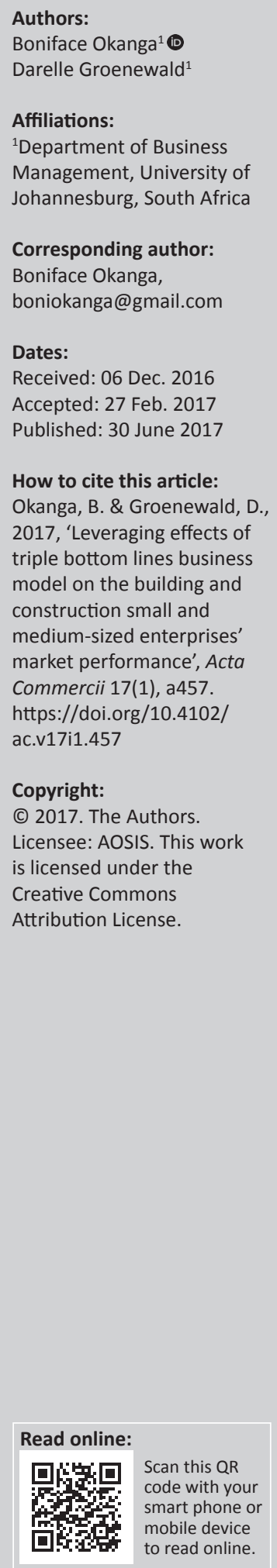

Orientation: Embracement of triple bottom line reporting as a driver of a firm's sustainability is a paradox puzzling most contemporary business executives.

Research purpose: The purpose of this research is to examine how effective alignment of the triple bottom line business model with building and construction operational activities leverages effective market performance of the small and medium-sized enterprises (SMEs) in the building and construction industry, so as to identify major paradoxes and the remedial business model that can be suggested.

Research design, approach and method: The study uses interpretivist research paradigm and exploratory qualitative research method to explore the opinions and perceptions of 30 judgementally drawn participants comprising managers and supervisors from 30 building and construction SMEs in Gauteng and KwaZulu-Natal provinces. Thematic analysis was used in the evaluation and interpretation of the interview data collected using a semistructured interview guide.

Main findings: A seemingly greater preponderance to pursue profitability at the expense of people and planet bottom lines was found to be common among most of the SMEs during the initial stages of their establishments and growth because of the need to attain the usually essential initial financial sustainability. Even though on attaining financial sustainability, some of the SMEs strive to achieve all the three bottom lines, most of the undertaken initiatives are often only aimed at improving compliance with relevant building and construction legislations.

Managerial implications: The study suggests a modified triple bottom line business model that the SMEs in the building and construction industry can replicate to effectively apply triple bottom line reporting as an edifier for effective market performance.

Contributions: The study offers a new theory for measuring the leveraging effects of the triple bottom line business model on the building and construction SMEs' effective market performance.

\section{Introduction}

Triple bottom line is an integral accounting framework emphasising interactive evaluation of people, planet and profits as three critical dimensions for measuring and improving a firm's performance (Ho \& Taylor 2007:123; Hubbard 2009:177; Schulz \& Flanigan 2016:449). In the accomplishment of such evaluations, it edifies conceptualisation and application of a combination of reactive and proactive measures that create a favourable work environment, improve employees' welfare and minimise ecological damages. In turn, these ignite employees' job satisfaction and productivity (Gordon \& Reddy 2010:19). It also enhances minimisation of operational costs often induced by significant reduction of hefty costs associated with fines and compensation for incidents and accidents causing injuries to the employees or the communities (Etzion \& Ferraro 2009:109). Yet, as triple bottom line abreast construction firms adopt more efficient operational methods and technologies, the resulting improved operational efficiency often also causes further reduction of operational costs. Subsequently, reduced operational costs enlarge a construction firm's overall profitability margin (Etzion \& Ferraro 2009:109).

Combined with the resulting positive reputation of a firm's overall consistency for the protection of the ecological environment, it is quite certain that as contrasted with non-triple bottom line abreast enterprises, effective embracement of the triple bottom line framework leverages a firm's overall competitiveness on the basis of cost and differentiation (Aimee, Boswell \& Davis 2011:55). Quite often, all these may also impact positively the building and construction businesses' continuity 
and sustainability in the increasingly discontinuous contemporary building and construction industry (Schulz \& Flanigan 2016:449). Although, it is evidently apparent the business values of triple bottom line reporting are abhorrently enormous, conventional tendencies in which profitability and increment of shareholders' value are prioritised above all business values seem yet a largely practised business phenomenon (Galamadien 2011:43; Niehaus 2016:25; Shezi 2013:16; Spicer 2013:1). Costs and business pressure linked to the essence of meeting daily operational overheads cause skewed approaches in which most of the small and mediumsized enterprises (SMEs) get strongly preoccupied with profitability to enrich shareholders' value at the expense of the planet and people dimensions of the triple bottom line business framework.

Overemphasis of profitability above people and ecological bottom lines causes negligence, which in turn induces underinvestments in the required safety and health improvement measures (Fauzi, Svensson \& Rahman 2010:134). Subsequently, such negligence can also cause related incidents that cause damage to the employees, the surrounding communities and the larger environment. In the long run, these tend to negatively affect cost savings and profitability (Galamadien 2011:43; Niehaus 2016:25; Shezi 2013:16; Spicer 2013:1). It is against this backdrop that while using an exploratory qualitative research method, this study explores the opinions of the managers and supervisors of the SMEs in the South African building and construction industry on the effectiveness of the application of the triple bottom line framework as an edifier for effective market performance. The motive of the study was to identify major paradoxes and to extract a remedial business model that can be suggested. Through such analysis, the value of the study is latent in the argument that it highlights why triple bottom line reporting is a strategic business concept with enormous values that cannot easily be ignored in the initiatives of improving SMEs' continuity and sustainability in the increasingly competitive and discontinuous contemporary South African building and construction industry.

\section{Literature review}

The concept of triple bottom line reporting is derived from Brundlant's (1987) report on sustainable development that highlights the essence of integrating the concept of sustainable development in strategic planning and business operation to facilitate resource utilisation in a way that enhances intergenerational equity (Hacking \& Guthrie 2008:73; Harrison \& Wicks 2013:97). Intergenerational equity is a fundamental concept linked to sustainable development that espouses the essence for the present generation or businesses to use the existing resources in a manner that leverages effective meeting of the needs of the present generation as well as the future generations (Suttipun 2012:12). By integrating the concept of sustainable development in strategic business planning and operation, the triple bottom line business model enhances optimisation of the usually limited resources and achievement of the desired sustainable development outcomes (Mish \& Scammon2010:12-26).
Besides the influence of sustainable development's notion of intergenerational equity, the emergence and evolution of the contemporary notions of the triple bottom line business model were also influenced by arguments in stakeholder theory (Suttipun 2012:12). It is the logic in stakeholder theory that besides significant values generated for the existing shareholders, a business's effective performance is also measured by values that an enterprise generates for its employees, customers and the general public (Stephen \& Meitner 2007:171). It implies executives' focus must be directed towards the creation of enormous profitability and returns on investments as well as generating the desired socioeconomic positive results. As businesses strive to achieve such financial, social and ecological outcomes, they tend to impact the overall well-being of the employees, customers and the general public. Such a view contrasts with the conventional accounting practice of shareholder value creation that had only a mandatory requirement for businesses to report on their accounting and financial performance (Schulz \& Flanigan 2016:449).

\section{Legitimacy theory}

Although profitability motive is a major driver of a firm's inquisitiveness of how to improve its performance, stringent application of stakeholder theory may undermine social responsibility reporting which is often critical for legitimising a business's operation in the midst of the increasingly demanding surrounding communities (Gordon \& Reddy 2010:19). A business's legitimisation among the surrounding communities often spawns improvement of a firm's corporate image, reputation and brand recognition. In turn, all these leverage a firm's differentiation and competitiveness. The reasoning in the business legitimisation approach is in tandem with the logic in the legitimacy theory (Tyrrell, Paris \& Biaett 2013:279). Legitimacy theory agitates for triple bottom line reporting as well as the logic that a business's sustainability depends on its rating among the surrounding societies (Stephen \& Meitner 2007:171). It is the fundamental argument in the legitimacy theory that the surrounding communities offer critical sources of resources and markets that determine a firm's overall sustainability and profitability. In effect, placing profitability and quest for enormous returns on shareholders' value above corporate social responsibility can therefore easily affect a firm's performance and sustainability (Gordon \& Reddy 2010:19).

Poor corporate social responsibility can induce negative media publicity that affects the reputation of the business. It can also infuriate certain quality and ethical issues, as well as escalating costs linked to direct litigation costs incurred as a result of regulatory breach, as well as hefty costs arising from fines or compensation for such a breach (Hacking \& Guthrie 2008:73). All these can affect a firm's financial bottom line and enrichment of shareholders' value. In other words, as firms embrace the triple bottom line business model, it spurs not only achievement of three bottom lines encompassing people, planet and profitability but also enhancement of a firm's approach to upholding the notions of sustainable 
development, a business's legitimatisation and stakeholder value creation (Hacking \& Guthrie 2008:73).

\section{Dimensions (people, planet and profitability) of the triple bottom line business model}

Conventionally, profitability is a business's raison $d^{\prime}$ etre (Tyrrell et al. 2013:279). However, it is the fundamental argument in the triple bottom line business model that as a firm strives to achieve profitability motives, it is also critical that they undertake measures that influence people's wellbeing as well as the preservation of and prevention of damage to the planet (Skouloudis, Evangelinos \& Kourmousis 2009:298). By upholding the well-being of the internal and external population and the planet, the proponents of the triple bottom line business model construe businesses may tend to leverage their profitability as compared to when people and planet dimensions are completely ignored (Skouloudis et al. 2009:298; Wang \& Lin 2007:106).

\section{People}

The people aspect of the triple bottom line business model constitutes employees, customers and the surrounding communities (Fauzi et al. 2010:145). Employees are pillars of the sustainability of the contemporary business operations. Levels of employees' contentment and satisfaction determine a firm's productivity, operational efficiency, cost control, quality management and the rate of customer satisfaction. In turn, all these leverage a firm's overall effective market performance (Fauzi et al. 2010:145). To improve employees' contentment and satisfaction, most business executives often prioritise improvement of employees' welfare, responsiveness to employees' needs and demands and development of mechanisms that enhance equitable and fair treatment (Wang \& Lin 2007:106). Accompanied by equitable and fair remuneration mechanisms, quests for improvement of employee welfare are also often latent in the undertaking of innovative measures that improve work conditions and environment as well as employee health and safety (Archel, Fernandez \& Larrinaga 2008:106).

Improved employee welfare minimises dissatisfiers. Subsequently, this bolsters employee commitment to effectively accomplish all activities required for the achievement of the desired business outcomes (Skouloudis et al. 2009:298; Wang \& Lin 2007:106). As employee welfare improves, it tends to also impact positively the improvement of customers' welfare as one of the critical components of people's aspect of the triple bottom line business model. Improved employee satisfaction spurs a firm's ability to offer better quality services and products to its customers (Ho \& Taylor 2007:123). Despite such enormous benefits, it is also often still critical that businesses develop and implement appropriate policies on how customer welfare and improved customer satisfaction can be leveraged. This may entail development and use of policies that facilitate identification and mitigation of incidents that may cause certain harmful effects on customers. It may also require frequent consultation with customers to improve their welfare (Mish \& Scammon 2010:12; Mitchell, Curtis \& Davidson 2008:67).

Because customers are also drawn from the communities, improved customer welfare may also catalyse improvement of the welfare of the surrounding communities. However, in addition to such measures, most businesses still often adopt clear policies on corporate social responsibility to assess and identify social programmes such as assistance of orphans, widows and youth programmes to ensure the business provides the desired benefits to the communities (Mitchell et al. 2008:67). These measures are usually accompanied by the development and use of techniques such as environmental impact assessment to evaluate and identify damaging effects of a firm's operation on the communities. Such analysis enhances necessary interventions to proactively minimise health and safety risks to the communities. In other words, as a business improves its people aspect of the triple bottom line business model, it tends to also spur improvement of the planet aspect of triple bottom line reporting (Mitchell et al. 2008:67).

\section{Planet}

Planet is the general ecological environment in which a business operates. It requires thorough analysis to evaluate the overall business implications on the ecological environments (De Ridder 2007:423). Common ecological damages are often linked to the destruction of natural habitat and pollution of water, atmosphere and the ecological systems (Galamadien 2011:43). Through thorough analysis, business executives are able to understand the implications of their businesses on the communities and the accompanying corporate social responsibility programmes that must be undertaken (Fell 2008:44). It is a business's concerns about such negative business implications and response that it takes to deal with the identified damaging ecological implications that influences the overall positive public perception about the business (Michigan City 2008:10). Ecological damages are often associated with three main negative implications that can affect a business's profitability and sustainability. These three negative implications are linked to risks of bad reputation that affects sales and profitability, cost of compensation for damages, cost of litigation and indirect costs that a firm has to meet as a result of engagement in the planet's damaging activities.

To avoid drawbacks arising from damage to the ecological environment, most executives often undertake improvement measures associated with investment in the appropriate technologies that minimise risks of pollution and damage to the ecological systems (Raushan 2015:69). It also requires frequent environmental impact assessment to evaluate and proactively mitigate the probable negative consequences of their business activities on the global planet. Investment in technologies that minimise risks of environmental damage is usually undertaken in conjunction with constant machinery repairs and maintenance as well as systems for machine replenishments (Raushan 2015:69). The undertaking 
of such measures minimises risks of using obsolete or dysfunctional machines that often either cause higher levels of noise or smoke that pollute the atmosphere. Use of defective machineries and equipment also causes risks of chemical leakages that can destroy soil fertility and the entire ecosystem (Slaper \& Hall 2011:4).

Because firms rely on their ecosystems, this can affect a firm's future management of the cost of inputs as well as sources of supplies that may turn out to be quite scarce (Slaper \& Hall 2011:4). Nonetheless, as firms undertake technologically proactive measures to minimise risks of ecological damage, the other more effective proactive measures are often latent in the use of environmental impact assessment (Dutta 2011:5). Environmental impact assessment diagnoses probable possible effects of a business's activities on the environment. This renders it possible for the executives to integrate measures that minimise the identified risks when the project becomes operational (Dutta 2011:5). Although real-time evaluation is often criticised for its reactionary nature, it is still critical that as business activities are being accomplished, real-time analysis is undertaken to facilitate identification of the level of compliance with relevant environmental regulations and policies (Dutta 2011:5). Real-time evaluations enable consistent identification and mitigation of deviations or new risks that cause damage to the ecological environment as they emerge.

However, it is not only the use of the appropriate technologies, environmental impact assessment and consistent real-time analysis that edifies minimisation of damage to the ecological environment (Tran 2015:19). Instead, the level of skillfulness and competencies of staffs may also determine whether an enterprise is able to act in a way that minimises risks of damage to the ecological environment (Tran 2015:19). Poor skilfulness and incompetence are usually the sources of mistakes, negligence, accidents and incidents that cause enormous damage to the ecological environment (Galamadien 2011:43). Improved employee skillfulness and competencies combined with an entrenched culture of good environmental practice therefore leverage the extent to which a firm is able to protect its planet aspect of the triple bottom line business model (Galamadien 2011:43). This implies improved efficiency resulting from improved employee satisfaction; the increased quest of an enterprise to minimise risks of damage to the ecological environment tends to instigate adoption of good business practices. This leverages a firm's overall profitability and returns on shareholders' value. It is against that backdrop that the proponents of the triple bottom line business model argue that instead of focusing on profitability, the executives must pursue measures that influence improvement of the people's welfare and the protection of the global planet (Niehaus 2016:25; Shezi 2013:16; Spicer 2013:1).

\section{Profits}

Profits are defined as the process through which all costs incurred in the production of different products and services are subtracted from total revenues to determine the percentage that remains as funds that a firm retains as the returns on the invested capital (Spicer 2013:1). However, risks may arise from the fact that such calculations are often only based on traditional accounting methods. The use of traditional accounting methods takes a narrow approach in which the calculation of profits is only limited to the evaluation of the revenues obtained as subtracted from the fixed and variable costs incurred in the production of such a product or service (Spicer 2013:1). It therefore suggests most of the process of evaluating profitability may not be undertaken holistically in the context of the new framework of triple bottom line reporting. The accounting framework of triple bottom line reporting focuses on not only the evaluation of fixed and variable costs but also cost of damage to the planet and people (Shezi 2013:16). Yet, as some businesses opt for a narrow approach for profitability analysis, poor analysis and integration of costs of damages to the planet and people may render some businesses to unknowingly miss all the incurred costs and end up operating at a loss. While using the old accounting methods that exclude social costs of production, a plant could still be profitable. However, when using methods in the triple bottom line business model, such a business can instead be interpreted to be making losses if there are other unconsidered social costs (Aimee et al. 2011:55).

Nevertheless, despite its leveraging effects on a firm's overall competitiveness, the process of integrating the triple bottom line business model in a business's operation is still usually determined by a combination of other factors. Without the integration of the thinking in the triple bottom line business model in the strategic management process, effective adherence to triple bottom line reporting may not easily be upheld by everyone in the organisation (Mitchell et al. 2008:67). Integration of the thinking in the triple bottom line business model cascades such thinking across all the departments and units of an enterprise. This renders it easy for all the employees and managers at all levels to understand critical activities that must be accomplished with only minimal management supervision to achieve all the people, planet and profit bottom lines (Slaper \& Hall 2011:4). The other critical predictors of the application of the triple bottom line business model are also often linked to investment in the necessary operational techniques and equipment as well as training and development of employees to accomplish different tasks more safely to minimise risks of harm or injuries to the employees and the larger ecological environment (Slaper \& Hall 2011:4). This is attributable to the fact that some of the major causes of harm to the employees or the environment are often linked to either the employees' negligence or machine failures (Ho \& Taylor 2007:123).

Unfortunately, even when employees are well trained and developed, a challenge often still arises from the poor integration of the concept of the triple bottom line business model in supply chains and value chains related activities, as well as the development of compatible culture and good 
governance. Good governance enhances transparency and accountability during the process of reporting. In certain cases, certain businesses tend to withhold relevant information from the general public in cases of severe damage to the environment that cannot easily be noticed unless an independent audit is conducted (Berger, Cunningham \& Drumwright 2007:132). In other words, theories imply that as construction firms invest in measures that improve people's well-being as well as minimise the planet's damage, it tends to bolster improved productivity, efficiency and clients' satisfaction that in turn also spur improved profitability and returns on shareholders' value (Suttipun 2012:12). All these impact the achievement of three bottom lines encompassing people, planet and profitability. However, it is still critical that the executives must evaluate the leveraging effects of the interactive triple bottom line (people, planet and profits) business model on a firm's effective market performance (Suttipun 2012:12). Such analysis can be accomplished by exploring how initiatives to respond to people's needs enhance improvement of employee satisfaction and the adoption of more efficient operational methods and systems (Raushan 2015:69). It must also entail assessment of the effects of such initiatives on the minimisation of health and safety risks and ecological damage, improved productivity, better response to customer needs and reduction of operational costs that in turn spur increment of revenue and profitability (Raushan 2015:69). Such analysis often facilitates identification of major changes and remedial improvement measures that can be undertaken. All these render it evident that triple bottom line reporting influences improvement of a business's sustainability. Nevertheless, limited research on the application of triple bottom line reporting by contemporary businesses seems to have affected the development of a triple bottom line reporting framework that the SMEs in the South African building and construction industry can easily emulate.

\section{Research statement}

A largely profit-driven approach used by most of the building and construction SMEs causes underinvestments in the people and planet aspects of the triple bottom line business model which in turn induces incidents that threaten health and safety of the employees and the surrounding communities as well as damage to the larger ecological environment. Although profit maximisation is often the motive of most building and construction SMEs, all these may instead tend to cause costs that reduce profitability, and even prospects of the sustainability of some of the building and construction SMEs.

\section{Research purpose}

The purpose of this research is to examine the leveraging effects of the triple bottom line business model on the building and construction SMEs' effective market performance, so as to identify major paradoxes and the remedial improvement business model that can be suggested.

\section{Methodology}

The study uses an interpretivism research paradigm and exploratory qualitative research method to explore the opinions and perceptions of 30 purposively drawn participants comprising managers and supervisors from 30 building and construction SMEs in Gauteng and KwaZuluNatal provinces (Clark 2010:428; Hewitt, Mitchell \& Torgerson 2008:23).

\section{Interpretivist research paradigm}

Interpretivist research paradigm refers to a research approach that uses a combination of methodologies and techniques to facilitate eliciting, analysis and interpretation of facts in their natural settings to reach logical conclusions on the phenomenon being evaluated. The use of the interpretivism research paradigm in this study was motivated by the need to unearth critical underlying facts that provide in-depth explanations of the approach used by the SMEs in the building and construction industry when seeking to align their operations with the practices required for the application of the triple bottom line business model. As compared to the positivist or deductive approach that relies on summarised numerical information, the interpretative research paradigm often offers richer information that enables analysis and identification of critical underlying facts explaining a particular phenomenon. Considering that evaluations of the leveraging effects of the triple bottom line business model on the effective market performance of the SMEs in the South African building and construction industry had not been explored by most of the previous studies, it was interpreted that the application of the interpretivist research paradigm would elicit richer information on SMEs' practices and behaviours as well as paradoxes faced when seeking to align their building and construction operations with the articulations in the triple bottom line business model. Through such an approach, it was construed that this research would be able to extract a grounded theory that can be further scientifically and statistically tested in a deductive or positivist research paradigm-based study. To accomplish this, the study used mainly the exploratory qualitative research method to interview and explore the opinions and perceptions of 30 purposively drawn participants comprising managers and supervisors from 30 building and construction SMEs in Gauteng and KwaZulu-Natal provinces.

\section{Sampling}

Purposive sampling refers to the sampling technique that uses certain defined criteria to draw and select only the participants considered to possess information critical for the study to reach logical conclusions on the phenomenon being investigated. Considering the complexity of the nature of the reasoning involved in the application of the triple bottom line business model and the fact that not all the managers of most of the SMEs are well educated, the application of purposive sampling was therefore critical for selecting only the SMEs in which most of the managers were identified to possess 
relevant knowledge and understanding of the essence of sustainability reporting in building and construction businesses. Also noting the extensive number of SMEs, the application of purposive sampling in conjunction with convenience sampling was therefore considered to render it easier for only certain provinces and SMEs to be selected from the vast number of SMEs spread across South Africa. To accomplish this, purposive sampling was used in conjunction with convenience sampling. In the first instance, the criteria for purposive sampling was set to ensure that the SME to be selected (1) was a formally registered building and construction SME, (2) had existed for at least the past five years or more and (3) that the employee, supervisor or manager to be interviewed had sufficient knowledge and understanding of issues associated with sustainability reporting as well as the dynamics of ensuring environmental protection when undertaking building and construction activities.

Seda (2016:5) highlights that there are about 667433 SMEs in South Africa of which 13\% (86 766) are in the building and construction industry. Convenience sampling was used to determine the provinces from which the sample building and construction SMEs could be drawn. In effect, KwaZulu-Natal and Gauteng provinces were selected because of their proximity to each other and lower transportation costs to move to and between the two provinces during data collection. From Seda's (2016:5) analysis, of these 13\% (86 766), 4120 are in Gauteng and 9002 are in KwaZulu-Natal. After using convenience sampling to identify the sample provinces, the study applied purposive sampling to draw 30 participants comprising managers and supervisors from 30 building and construction SMEs that were based in Gauteng and KwaZulu-Natal provinces in the period between April and 20 October 2016. This led to interviews that were accomplished using a semi-structured interview guide.

\section{Interviews}

Using a semi-structured interview guide, participants were asked to list and describe the integrated mechanisms that they have put in place to improve achievement of people, planet and profitability bottom lines. Besides evaluation of their views on the business values that have so far been gained from the alignment of their operational activities with the triple bottom line business model, participants were also asked to comment on the major paradoxes of the strategic initiatives undertaken to improve achievement of people, planet and profitability bottom lines. Given the challenges that they are presently facing, the opinions of the participants were also further sought on the improvement measures that they would like to suggest for improving the effectiveness of triple bottom line reporting. The obtained findings were thematically analysed.

\section{Data analysis}

Results of the obtained qualitative data were thematically analysed by reading and rereading the interview data, extracting key themes and subthemes that explain practices and behaviours as well as paradoxes that the SMEs in the building and construction industry encounter when applying the triple bottom line business model (Figure 1) (Morse 2010:483). The results of thematic analysis in Figure 1 were triangulated with the key theoretical findings to extract a business model that modifies the application of the triple bottom line business model in the building and construction context for the SMEs in the building and construction industry in South Africa to easily emulate (Figure 2). Nevertheless, as the study and the analysis were being undertaken, qualitative validity of the study was also assessed by evaluating credibility, transferability, dependability and conformability of the study.

\section{Qualitative validity}

Credibility that deals with the internal validity of the study was enhanced by ensuring that the description and interpretation of the findings perfectly reflected the opinions of the participants in the study. In this process, critical analysis of the interview data was undertaken to ensure that the emerging themes commonly reflect the opinions of the interviewed participants. Transferability that also edifies the external validity of the study was undertaken by assessing the extent to which the study can easily be generalised. To ensure generalisability of the study, convenience sampling was used to at least draw sample SMEs from two provinces (Gauteng and KwaZulu-Natal). This improved the extent to which the opinions of the participants from Gauteng were corroborated by the views of the participants from the SMEs in KwaZulu-Natal. The findings of such analysis were triangulated with the results of empirical studies on SMEs' sustainability reporting in South Africa to discern the extent to which the findings on the SMEs' application of triple bottom line reporting can be generalised not only to the SMEs in the building and construction industry but also across the other businesses that deal in ecologically damaging activities.

As such measures were being undertaken, dependability that deals with the reliability of the study was undertaken by ensuring that the interview guide used in the process of data collection reflected questions aligned to the fundamental research questions of the study (Clark 2010:428; Hewitt et al. 2008:23). This facilitated ensuring interviews elicited information relevant for necessary conclusions to be reached on the practices and behaviours as well as paradoxes that the SMEs in the building and construction industry encounter when applying the triple bottom line business model. This was accompanied by fact checking and rechecking whether all the critical and sufficient information had been obtained and extending the period of data collection, which was initially scheduled to end on 15 August 2016, to 20 October 2016. The other measures for improving dependability of the study entailed checks on the qualifications and experience of the participants during the purposive sampling process to ensure that they had the appropriate knowledge and information to participate in the debate on the application of triple bottom line reporting by contemporary businesses (Clark 2010:428). 


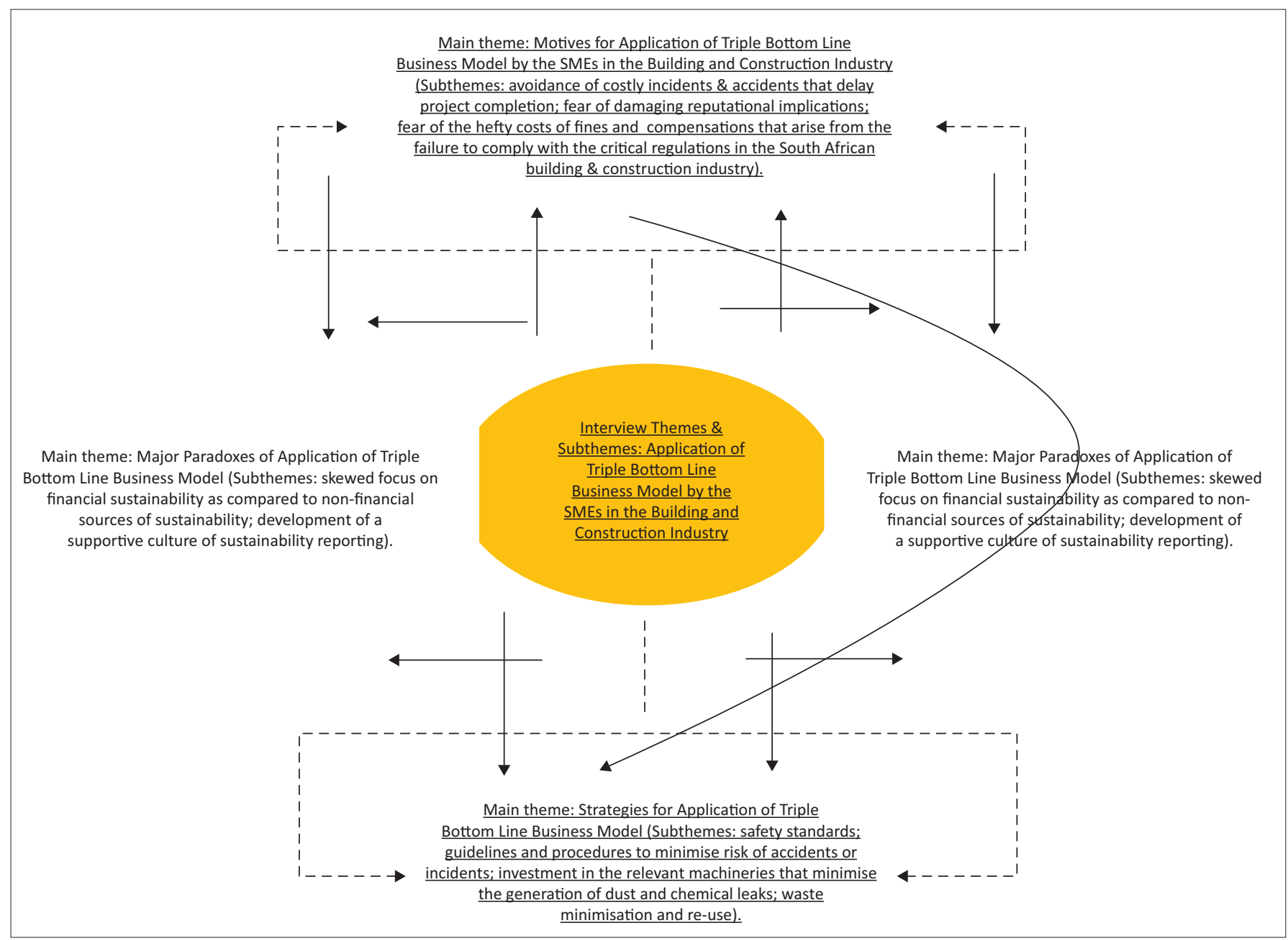

Source: As extracted from the interpretation of the key interview themes on the application of the triple bottom line business model by the small and medium-sized enterprises in the building and construction industry

FIGURE 1: Interview themes: Application of triple bottom line business model by small and medium-sized enterprises in the building and construction industry.

In other words, fact checking and rechecking as well as triangulation of the interview findings with the theoretical findings also improved confirmability that also refers to the extent to which the study was objectively undertaken. Further analysis to improve credibility, dependability and confirmability of the study was undertaken by contrasting and comparing the views of the participants from different SMEs to assess whether such views corroborated each other. These were undertaken in conjunction with triangulation of the interview findings in order to assess whether the gaps emerging from the approach used by the SMEs can be filled using any of the existing theories. It also enhanced analysis of how gaps identified in the existing theories can be filled by new discoveries from the practices of the building and construction SMEs when using the triple bottom line business model. The interview results are as presented and discussed in the next sections.

\section{Results}

Findings of the study are presented in this section according to the two main subsections:

- Triple Bottom Line Reporting: Practices and Behaviours of the SMEs in the South African Building and Construction Industry
- Paradoxes: Triple Bottom Line Reporting by the SMEs in the South African Building and Construction Industry

The details of the findings are evaluated as follows.

\section{Triple bottom line reporting: Practices and behaviours of the small and medium-sized enterprises in the South African building and construction industry}

To enhance understanding of the practices and behaviours of the SMEs in the South African building and construction industry, interview findings were analysed and presented according to main themes encompassing motives of the application of the triple bottom line business model by the SMEs in the South African building and construction industry and strategies for the application of the triple bottom line business model by the SMEs in the South African building and construction industry.

Motives for the application of the triple bottom line business model by the small and medium-sized enterprises in the South African building and construction industry

It is highlighted in Figure 1 that the motives for the application of the triple bottom line business model by the SMEs in the 
South African building and construction industry are often linked to subthemes encompassing avoidance of costly incidents and accidents that delay the completion of projects as scheduled, fear of the damaging reputational implications that often arise from negligence causing incidents and accidents and fear of hefty costs of fines and compensations that arise from failure to comply with critical regulations in the South African building and construction industry.

\section{Avoidance of costly incidents and accidents that delay completion of projects as scheduled}

It emerged from the analysis of the interview findings that most of the SMEs tend to use an approach akin to the triple bottom line business model to minimise risks of accidents or incidents that can interfere with the effectiveness of the process of project implementation. This is often undertaken by putting in place the necessary safety and environmental protection measures. Reasons were found to be associated with the fact that accidents tend to cause injuries or deaths of critical staff members that may be difficult to replace. Even if accidents do not occur, the analysis of the interview findings still indicated the need to protect the environment also influences decisions of some of the SMEs in the building and construction industry. This is attributable to the fact that in case of environmental incidents, inspectors from government and environmental bodies often intervene to temporarily stop the process of project implementation. In effect, to avoid interference with the schedules of project implementation, most of the SMEs tend to take precautionary measures by ensuring that their activities do not impact negatively on the environment. Such a finding is corroborated in the opinions of one of the managers of the SMEs in New castle in KwaZulu-Natal who stated that:

'Constant inspections by government building and construction inspectors, health inspectors and environmental bodies tend to force to us to put in place the necessary measures for minimising harm on the communities or damage of the environment. It is important because if they find that you are causing environmental damage or exposing employees to health and safety risks, they stop the project until you have put in place the necessary preventive measures. This is because in most of the cases, deaths and accidents causing injuries have been occurring as a result of the failure of some of the building and construction firms to put in place the necessary facilities. Some of the SMEs are quite reckless to the extent to that if they are involved in certain constructions, they tend not to clean up and just leave like that. This has caused most of the municipalities to be strict by constantly inspecting and stopping projects that seem not to be complying. When they stop you, it means you cannot continue and finish the project within the stipulated time. So, to avoid dissatisfactions from clients, we tend to take the necessary preventive measures to avoid accidents or incidents causing injuries, deaths or damage of the environment.' (Participant 11, male, 33 years)

In other words, despite the wider recognition of the need to protect the environment as a prerequisite for avoiding interference with the process of project implementation by government inspectors, thorough analysis of the interview findings also indicated that the notion of triple bottom line reporting is still not understood by some of the SMEs in the building and construction industry. In effect, the initiatives to foster the respect of the surrounding environment and avoidance of damage to the surrounding communities tend to be undertaken by some of the SMEs not for the purpose of facilitating triple bottom line reporting, but because of the need to avoid costly incidents and accidents that delay the completion of projects as scheduled. In effect, it emerged from the interview findings that although some of the SMEs use measures that minimise health and safety risks to employees as well as environmental damage, in their reports it is still often evident that it is the profitability outcomes that are emphasised. Besides such reasons, it is reiterated in Figure 1 that findings also revealed fear of the damaging reputational implications that often arise from negligence causing incidents and accidents as the other reason why some of the SMEs in the building and construction industry are forced to adopt building and construction practices and behaviours that leverage the effective use of the triple bottom lines' business model.

Fear of damaging reputational implications arising from negligence causing incidents and accidents

Implicitly, it emerged from the interview findings that the accomplishment of the process of project implementation without incidents or accidents is often interpreted by the general public and potential clients as demonstrating good work that the building contractor can do. In effect, most of the interviewed managers and supervisors noted that as much as it is costly to adopt and implement certain measures, they often tend to do so to avoid incidents and accidents that can affect their reputations. As thematic analysis of the interview findings indicated, this is often accomplished by ensuring that the client has an appropriate building plan bearing all the health and safety features. The other measures often involved developing and strictly using methods prescribed for removal and cleaning of waste as the construction is underway. Some of the SMEs noted that as they are subcontracted to the big construction firms, they also tend to learn better practices for minimising accidents and incidents as well as ecological damage, and upon completion of such subcontracts, they also apply the practices in their own building and construction processes. In the context of the interview findings, such measures often improve minimisation of incidents and accidents that also subsequently influence improvement of their building and construction reputation. However, for the SMEs in the rural areas, one of the managers stated that:

'If you are operating mainly in the rural areas, demands from clients can force you to engage in activities that subsequently cause damage to affect your reputation. Some of the clients do not often have building plans and if you advise them to develop one, they often refuse on the basis that they do not have money for building plans. Others pressurise you to hurry with the construction process to the extent that after the completion of the project, defects such as cracks on the walls emerge immediately. This is because during the construction process, the newly constructed walls will have not been left to dry before continuing. 
It is such minor errors that usually turn into major incidents and accidents to affect health and safety commitments as well as the reputation of the building and construction firm involved in such a project.' (Participant 29, female, 44 years)

As much as fear of damaging reputation resulting from negligence is the reason why some of the SMEs adopt measures akin to the measures for enhancing effective application of triple bottom line reporting, it is still evident that such fear also forces the use of the triple bottom line business model by some of the SMEs in the building and construction field. In other words, the interview findings imply that fear of damaging reputation seems to echo views in most of the theories on the triple bottom line business model (Slaper \& Hall 2011:4). It is the argument in most of the theories on triple bottom line business reporting that as much as most of the businesses focus on profitability and ignore people and planet, increased negligence resulting in damaging reputation can affect a firm's market performance and profitability (Slaper \& Hall 2011:4).

Nevertheless, in addition to fear of damaging reputation, it is also reiterated in Figure 1 that the other subtheme that emerged from the analysis of the interview findings was linked to fear of hefty costs of fines and compensations that arise from failure to comply with critical regulations in the building and construction industry.

Fear of the repercussions of failure to comply with relevant building and construction regulations and legislations

The analysis of the interview findings revealed that some of the SMEs reiterated that fear of hefty costs of fines and compensations arising from failure to comply with critical regulations in the building and construction industry forced some of the SMEs to adopt measures that improve triple bottom line reporting. From the analysis of the findings and triangulation with the findings of different prior empirical studies conducted on sustainability reporting in the building and construction industry, such legislations were noted to include the National Environmental Management Act (NEMA) No. 107 of 1998, Occupational Health and Safety Act No. 85 of 1993, Consumer Protection Act No. 68 of 2008, Construction Industry Development Board Act No. 38 of 2000 and the National Building Regulations and Building Standards Act No. 103 of 1997. Some of the participants noted that failure to comply with these legislations is often associated with serious repercussions that can cause hefty fines and compensation for injuries. This reduces profitability. In certain instances, some of the managers revealed that failure to comply or involvement in major incidents and accidents can even cause withdrawal of licences. This affects the future performance and sustainability of some of the SMEs. Such a finding is accentuated in the opinions of one of the supervisors in a construction firm in Pietermaritzburg in KZN, who stated that:

'There are building and construction regulations that govern our businesses. That means whether you want it or not, you have to comply irrespective of whether it costs a lot of money to implement the required measures. But also, it depends on the nature of the building and construction contract. If you are subcontracted to a large construction firm, you either comply with the safety requirements and health concerns or the contract is terminated without compensation. However, in most of the cases, to build good reputation among the communities, it is important to do things in the right way because if clients experience safety problems or communities complain, it can turn difficult for anyone else within that community to engage you again in the construction of smaller houses such as RDP houses.' (Participant 5, female, 29 years)

However, because in most of the cases, some of the SMEs comply with these legislations just for the purpose of avoiding fines and damaging reputation, it also emerged from the views of some of the participants that there are often stronger tendencies for some of the SMEs to accomplish activities that facilitate compliance as mere formalities. In effect, when analysis of their reports is undertaken, it is often evident that there is stronger emphasis on profitability rather than people and planet bottom lines. This affects the entrenchment of a culture of triple bottom line reporting. Nevertheless, as most of the SMEs in the building and construction industry seek to improve compliance with relevant legislations to either avoid costs or emergence of damaging reputation from bad practice and behaviours, the themes presented in Figure 1 imply that they also tend to use a combination of different strategies to entrench a culture of good environmental as well as health and safety practices.

\section{Strategies for the application of the triple bottom line business model by the small and medium-sized enterprises in the South African building and construction industry}

Thematic analysis of the interview findings on the strategies for the application of the triple bottom line business model by the SMEs in the building and construction industry revealed two subthemes linked to (1) safety standards, guidelines and procedures to minimise risks of accidents or incidents and (2) investment in relevant machineries to minimise pollution and environmental damage.

\section{Safety standards, guidelines and procedures to minimise} risks of accidents or incidents

To improve SME capabilities to achieve three bottom lines encompassing people, planet and profits, findings revealed that some of the SMEs agreed that they tend to develop internal safety standards, guidelines and procedures to minimise risks of accidents or incidents. They explained that internal safety and health guidelines and procedures guide the employees on the critical activities that they need to accomplish to avoid damage, injuries or deaths of employees or members of the surrounding communities. As one of the managers noted, the development and monitoring of compliance with the internal safety and health standards facilitates practicalisation and compliance with relevant building and construction regulations and legislations. This is attributable to the fact that in most of the cases, it is the employees who are the sources of safety, health and 
environmental incidents that can affect embracement of the triple bottom line business model. In effect, the establishment of relevant safety, health and environmental standards enhances improvement of their understanding of what they need to avoid in order to minimise risks of accidents and incidents. However, one of the managers working for an SME involved in mine construction in Rustenburg noted that:

'In most of the cases, it is not lack of relevant internal safety, health and environmental standards, guidelines and procedures which are challenges causing incidents and accidents as well as damage of the environment. Instead, it is the employees' negligence. Even if you put in place the necessary safety, health and environmental policies, employees in the midst of lack of supervision tend to develop their own procedures. These procedures are often ingrained with negligence, mistakes and errors that expose not only them to danger, but also the surrounding communities as well as the environment. Some of the employees are not well educated. So even if you train them, they still try what they were told not to do, thereby causing safety, health and environmental incidents.' (Participant 14, female, 48 years)

In other words, as it emerged from the opinions of some of the managers, as relevant internal safety, health and environmental standards are put in place, it is often accompanied by training and development of the employees. This improves their skills and competencies to minimise frequent occurrences of incidents that are often linked to the employees. However, considering that most of the building and construction SMEs tend to use on-the-job training and development programmes rather than interplay of practicals and theories, in most of the cases, some of the supervisors noted skills and competencies required for minimising safety, health and environmental incidents are often not acquired more effectively by the employees. With time, as findings revealed, such incompetencies and lack of skills tend to turn into the sources of incidents and accidents that affect the safety and health of the employees and members of the surrounding communities. Such incidents also tend to be latent in pollution and littering of land as a result of failure to clean the construction site after the completion of the building and construction projects. Besides the development of internal safety standards, guidelines and procedures, the analysis of the interview findings also revealed that investment in relevant machineries is also often undertaken by some of the building and construction SMEs to minimise pollution and environmental damage.

Investment in relevant machineries to minimise pollution and environmental damage

To ensure building and construction activities are accomplished in a way that minimises damage to the environment or avoidance of harm in the surrounding communities, Figure 1 highlights findings to have revealed some of the SMEs to consider investment in relevant machineries that minimise the generation of dust and chemical leaks. This is often accompanied by the adoption of waste minimisation and reuse mechanisms during building and construction processes. The use of relevant machineries was found to be critical in cases of demolition of buildings that need to be reconstructed. In such cases, some of the supervisors reiterated that machineries used tend to determine the amount of dust and noise generated. Other instances in which the use of appropriate machineries was found to be critical for minimising environmental pollution and damage was noted by the participants to be associated with the mixing of concretes. In that process, leakage of dirty water was found to cause health risks to the children in the surrounding communities, especially in the rural areas, just as is the case with the trucks being used that may cause higher decibel levels of noise. To prevent such risks, most of the SMEs stated that investment in the appropriate machineries is often considered a prerequisite. As investment in the appropriate machineries is being undertaken, some of the participants revealed that most of the SMEs are also investing in recycling and reuse of building and construction waste. For instance, they explained that some of debris that arises from demolition activities is often crushed and mixed with gravels that are further reused in the creation of concrete floors. This is echoed in the views of one of the interviewed managers working in his own building and construction SME in Pretoria, who explained that:

'Over time, innovative measures have been developed and adopted to facilitate recycling and reuse of building and construction wastes. This is because requirements from the environmentalists in as far as dumping is concerned are turning to be quite demanding on us. You have to locate the appropriate site for dumping the construction wastes, pay for dumping and transportation as well. This tends to be costly as compared to recycling and reusing most of the wastes back into the building to minimise risks on the environment and costs. It also reduces costs of building materials such as gravels and stones'. (Participant 8, male, 55 years)

On the other hand, some of the participants revealed that as copper and steel materials are generated from cutting and recutting of materials during the construction process, initiatives are also undertaken to partner with companies that engage in the collection of the remaining wasted copper and steel pieces for further smelting and reuse in the other valuable commercial purposes. All these were noted in the findings to minimise the damaging effects of construction activities on people and planet.

However, as it emerged from the interviews, Figure 1 indicates that despite initiatives undertaken by most of the SMEs in the building and construction industry, efforts to attain three bottom lines encompassing people, planet and profits are often still saddled with a combination of yet unresolved paradoxes.

\section{Paradoxes: Triple bottom line reporting by the small and medium-sized enterprises in the South African building and construction industry}

In line with the illustration in Figure 1, findings revealed that major paradoxes of triple bottom line reporting by most of the SMEs in the South African building and construction 
industry are often linked to SMEs' skewed focus on financial sustainability as compared to non-financial sustainability and poor development of a culture of sustainability reporting. The details are evaluated as follows.

\section{Skewed focus on financial sustainability as compared to non-financial sustainability}

It emerged from the analysis of the interview findings that major paradoxes of the application of triple bottom line reporting among most of the SMEs in the building and construction industry are often linked to the difficulties of balancing profitability motives with the drive to achieve objectives linked to the improvement of the welfare of the people and the protection of the environment. This is attributable to the fact that most of the SMEs in the building and construction industry struggle with the management of overheads just like the SMEs in the other sectors. Such a finding was well elucidated in the opinions of one the interviewed managers who manages her own building and construction SME in Soweto by building RDP houses. She argued that:

'As much as prevention of damage on the environment and the surrounding communities is important, most of the critics do not understand the financial conditions and circumstances under which we operate. Some of us established our businesses after acquiring loans. That responsibility of repaying the loan and also meeting personal obligations render quest for profitability our main purpose. In that process, I must say that in certain circumstances, some of the SMEs tend to flout investments in certain requirements to minimise damage on the environment or prevent risks of harm on the surrounding communities. It is difficult for the construction firm that was just established two or five years ago to start its business by protecting the environment rather than searching for profits.' (Participant 3, female, 51 years)

As further analysis of the interview findings revealed, the implications of lack of adequate financial resources are often latent in the fact that in the initial stages and the mid-periods of SMEs' growth, the importance for balanced triple bottom line reporting is often underrated in favour of the initiatives for improving the overall financial sustainability. Reasons were found to be linked to the fact that after the attainment of financial sustainability, it tends to become easier to adopt mechanisms for improving the welfare of the people and the protection of the environment. While upholding such reasoning, most of the SMEs construe commencing the process of operation by striving to achieve all the three bottom lines to be costly and affect the sustainability of the business. The basis of such reasoning was found to be echoed in the questions posed by one of the senior managers as follows:

'If you have a business, are you going to start by paying attention to the wellbeing of the people and the ecological environment or by ensuring that you first accumulate the necessary financial resources?' (Participant 6, male, 40 years)

In other words, it was the opinion of most of the SMEs that it is important to gain financial sustainability prior to achieving objectives linked to people's welfare and protection of the planet. It emerged from the findings that reasons are often linked to the fact that the improvement of the welfare of the people and the protection of the planet also require financial investments that can only be undertaken after the firm has improved its financial capabilities. Besides skewed focus on financial sustainability, other paradoxes affecting the effectiveness of triple bottom line reporting by most of the SMEs were also noted to be related to poor development of a culture of sustainability reporting.

\section{Poor development of a culture of sustainability reporting}

Because triple bottom line reporting is voluntary for SMEs, it is often quite common for SMEs to not act honestly. In these processes, most of the SMEs tend to only integrate the three bottom lines in the process of accomplishment of different construction activities if it is apparent that if precautionary measures were not taken, the surrounding communities and the planet would be adversely affected and the public would be alerted. The fear is that once the public is alerted, it can lead to incidents that affect the reputation of the business or even attract legal suits. To avoid that, some of the SMEs tend to evaluate the implications of the cost of non-compliance and, if found feasible, the companies tend to ignore the people and the planet bottom lines. Such approach affects the evolution and development of a culture of sustainability reporting among most of the SMEs in the building and construction industry. Poor development and evolution of a culture of sustainability reporting among SMEs are often further affected by poor supervision by government inspection personnel from the Department of Labour, Environmental Agencies and Building and Construction Bodies to effectively monitor compliance. Such a finding is well explained in the response of one of the supervisors working for a construction company in Durban, KZN, who stated that:

'Most of the building and construction SMEs operate in rural areas which are in certain cases deeply isolated. This affects constant monitoring by the usually few government inspectors. Consequently, the decision to comply or not to comply may remain that of the building and construction SME. In most of the cases, as the SME continues to operate in isolation, it tends to cause circumstances where they invent their own practices in regard to activities such as electrical installations that may not necessarily be effective for minimising damage on the environment or risks of harm on the surrounding communities.' (Participant 26, male, 50 years)

In other words, it also emerged from the findings that as supervisors rely only on a checklist of the areas to be evaluated, likewise most of the SMEs also just tend to take initiatives to only adhere to such outlined areas rather than the undertaking of the required voluntary initiatives to balance the achievement of profitability motives with the objectives for improving the well-being of the people and the planet. Even if some of the SMEs strive to develop a strong culture of sustainability reporting, it still emerged from the analysis of the findings that as long as such SMEs are frequently involved in a series of subcontracts awarded by 
bigger construction firms, the development of a culture of sustainability reporting tends to be affected. This is attributable to the fact in subcontracts, it is the responsibility of the bigger construction firms to comply and put in place measures that influence respect of the people's welfare and protection of the environment. In effect, uninterrupted involvement in a series of subcontracts affects the extent to which SMEs are able to invest in their own systems such as safety and environmental protection measures.

\section{Discussion}

Effective embracement of the triple bottom line (people, planet and profits) business model is a driver of the sustainability of the SMEs in the increasingly precarious contemporary construction industry (Aimee et al. 2011:55). It enables a firm to balance the drive for profitability motives with strong emphasis on the minimisation of damage to the planet or harm to the surrounding communities. All these translate into improved profitability, better relationship with the communities and customers as well as reputation that edifies a firm's overall rating and competitiveness among rivals (Suttipun 2012:12). Improvement of the welfare of the people or initiatives to effectively meet the needs and demands of the employees influences the improvement of employee satisfaction, commitment and motivation. In turn, all these interactive positive effects of such business values may leverage improvement of productivity and better quality of customer services. Better quality of customer services is often significantly associated with the increment of customer attraction, profitability and returns on shareholders' dividends (Raushan 2015:69). The fact that effective embracement of the triple bottom line (people, planet and profits) business model also minimises damages caused by the building and construction activities to the environment implies it also enables a firm reduce costs of non-compliance. Costs of non-compliance often arise from fines, litigation, compensation and riots by the environmentalists and pressure groups (Raushan 2015:69). As such risks and costs reduce, their positive implications are often latent in the improved reputation for better building and construction practices that in turn spur increment in the rate of clients' attraction and a construction firm's overall clientele base.

In effect, it is certainly quite evident that although most firms focus on profits at the expense of the people and the planet, initiatives undertaken by businesses to improve the wellbeing of the people and planet can certainly leverage a firm's competitiveness, effective market performance and profitability (Slaper \& Hall 2011:4). Unfortunately, despite a positive approach undertaken by some of the SMEs in the building and construction industry, a seemingly greater preponderance to pursue profitability at the expense of the people and planet bottom lines seems to yet emerge strongly among most of the SMEs during the initial stages of their establishments and growth. Even though at the later stages of attaining financial sustainability, some of the SMEs tend to engage in business approaches that facilitate balanced achievement of people, planet and profitability bottom lines, lack of a culture of triple bottom line reporting causes some of the SMEs to undertake approaches not just aimed at facilitating achievement of all triple bottom line objectives, but mere compliance with legislations such as the National Environmental Management Act (NEMA) No. 107 of 1998, Occupational Health and Safety Act No. 85 of 1993, Consumer Protection Act No. 68 of 2008, the Construction Industry Development Board Act No. 38 of 2000, and the National Building Regulations and Building Standards Act No. 103 of 1997. Combined with limited research and lack of a suitable triple bottom line business model that the SMEs in the building and construction industry can emulate, all these were found to saddle stronger embracement of the triple bottom lines' business model as an edifier for effective performance of the SMEs in the building and construction industry.

\section{Managerial implications}

If the executives of the SMEs in the building and construction industry are to effectively align their business operations with the triple bottom line business model, it is critical to use five steps in the remedial business model in Figure 2. The remedial business model in Figure 2 offers new insights on the basis that as much as most of the authors such as Dutta (2011:5), Fauzi et al. (2010:134) and Tran (2015:19) only elucidate on how to achieve people, planet and profits' bottom lines, the model in Figure 2 instead modifies such a framework by adding certain critical key success factors that SMEs need to consider to leverage the alignment of building and construction operational approach with the triple bottom line business model. While applying the business model in Figure 2, the first step will require the evaluation and improvement of the people dimension of the triple bottom line business framework. The people dimension of the triple bottom line business model further comprises three more sub-dimensions encompassing employees, customers and the communities. Improvement of the sub-dimension of employees can be accomplished by responding to employees' demands for suitable work environment, health and safety concerns, fairness and justice and good remuneration. The response to the needs of customers can be undertaken by adopting measures that improve a building and construction firm's responsiveness to their quality needs, health and safety needs, efficiency and improvement of customer values. As On the other hand, the needs of the communities can be met through minimisation of pollution, damage to the ecological environment, health and safety incidents and corporate social responsibility to support the surrounding communities.

As such measures are being undertaken, critical success factors that must be interpolated to improve the application of the triple bottom line business model are outlined in step 2 to encompass recognition of the embracement of the triple bottom line business model as an investment rather than costs, a culture of balancing good business practice with environmental sustainability, development of health and safety construction practice and investment in the appropriate machineries to minimise damage on the ecological environment. The integration of these critical success factors 


\section{Step 1: People}

employees [suitable work environment, health \& safety concerns, fairness and justice \& good remuneration], Customers [quality needs, healthy \& safety needs, efficiency and improvement of customer values] \& Communities [minimisation of pollution, damage to the ecological environment, health \& safety incidents \& corporate social responsibility to support communities].

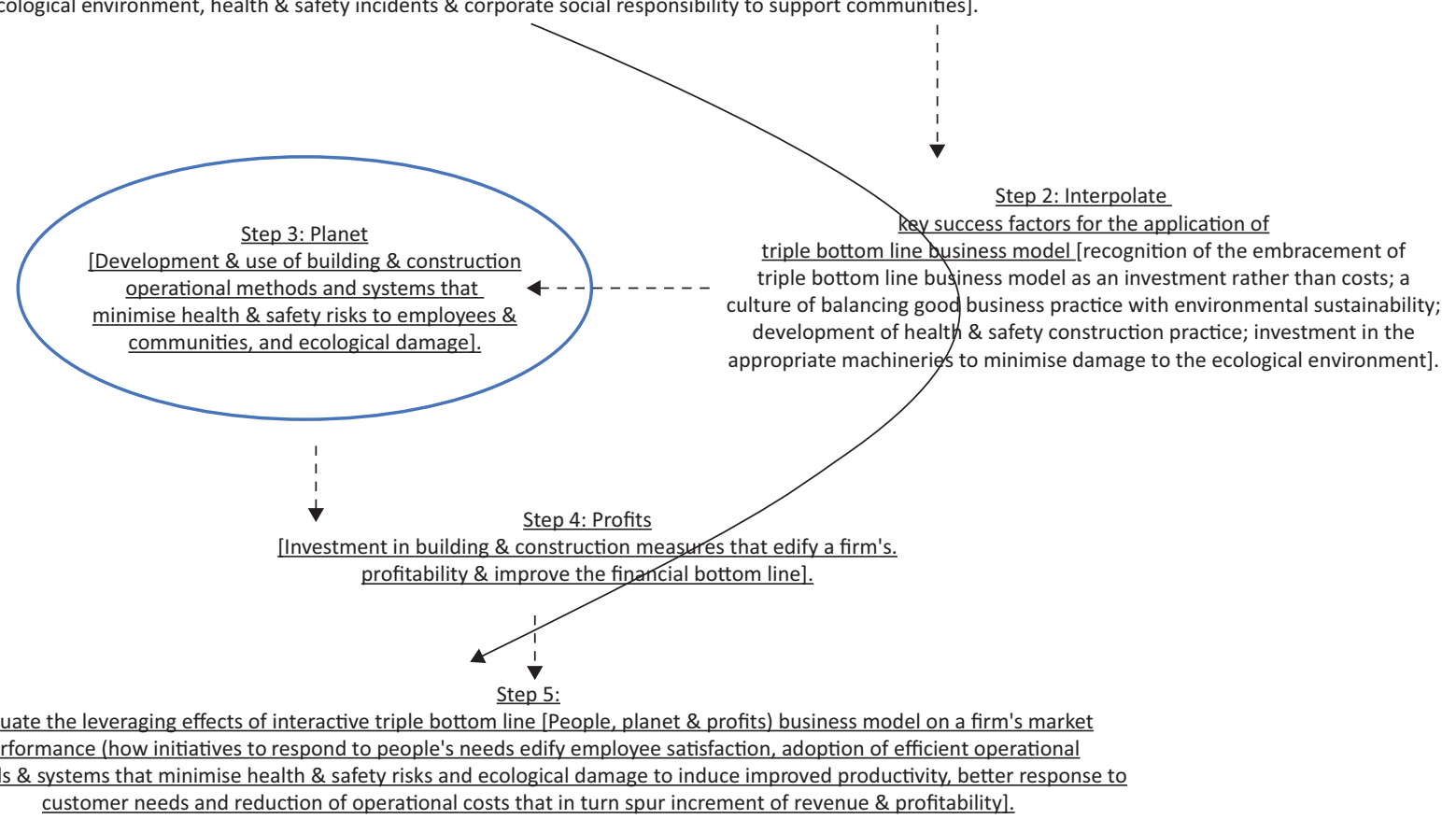

Source: As extracted from the triangulation of different theories on triple bottom line business philosophy (Casanova 2010:132; Dutta 2012:652; Ekwueme, Egbunike \& Onyali 2013:212; Gordon \& Reddy 2010:19) with interviews on the use of triple bottom line business philosophy by the small and medium-sized enterprises in the South African building and construction industry

FIGURE 2: A remedial business model for leveraging the effects of the triple bottom line business model on the building and construction small and medium-sized enterprises' market performance.

not only prepares the foundation for improving the people dimension of the triple bottom line business model but also the planet dimension. The minimisation of damage to the planet would require the adoption of building and construction operational methods and systems that minimise health and safety risks on employees and communities, and ecological damage.

As such measures are accompanied by the application of step 2 , which requires the interpolation of key success factors for the application of the triple bottom line business model, the improvement of the profit dimension of triple bottom line reporting may be undertaken in step 4 by improving investment in building and construction measures that edify a firm's profitability and improve the financial bottom line. After the application of the triple bottom line business model has being undertaken, it is indicated in step 5 that it is critical to evaluate the leveraging effects of the interaction between people, planet and profit bottom lines on a firm's market performance. To reach logical conclusions on whether the application of the triple bottom line business framework is leveraging a construction firm's market performance, the critical factors that must be explored include evaluation of how the initiatives to respond to people's needs edify employee satisfaction. It also requires adoption of efficient operational methods and systems that minimise health and safety risks, as well as ecological damage to induce improved productivity, better response to customer needs and reduction of operational costs that in turn spur increment of revenue and profitability.

\section{Suggestion for further research}

Alignment of business operation to a triple bottom line business model induces enormous positive business outcomes that leverage a construction firm's overall performance and sustainability. However, it emerged from the findings that the total integration of the triple bottom line business model in construction operations by most of the SMEs in the building and construction industry is still often saddled by skewed focus on financial sustainability as compared to non-financial sustainability. The other challenge was found to be linked to a lack of an entrenched culture of sustainability reporting. To respond to such challenges, the study suggested the business model in Figure 2 as the triple bottom line business model that can be replicated by the SMEs to leverage the total integration of the triple bottom line business model in construction operations as a prerequisite for sustainability in the increasingly precarious contemporary building and construction industry. However, future research can still explore the techniques or tools for measuring the business impact of using such a triple bottom line business model.

\section{Acknowledgements}

The authors would like to thank and appreciate the assistance and cooperation offered by the civil engineers, site managers and supervisors from the SMEs that volunteered to participate in this research. They also acknowledge and thank them for the information, both documentary and interview data that rendered this research a success. Hopefully, the findings of the study will provide 
detailed insights that will influence their future strategic decisions on how to adopt the triple bottom-line business model as one of the performance improvement strategies. The authors also advance their appreciation and gratitude to both the Department of Business Management and the Postgraduate Centre in University of Johannesburg for providing necessary funds that rendered the study that would have been impossible possible.

\section{Competing interests}

The authors declare that they have no financial or personal relationships that may have inappropriately influenced them in writing this article.

\section{Authors' contributions}

O.B. initiated the topic and research project, designed the framework for the primary study, collected the necessary interview data, analysed and wrote the findings. D.G. designed the framework of the study outlining critical activities that must be accomplished and developed the literature, and put the whole document together and reworked to ensure chronological flow of the manuscript prior to submission for review. Finally, O.B. reworked the manuscript after reviews and presented it to D.G. for approval prior to submission for approval by the editor of Acta Commercii.

\section{References}

Aimee, J., Boswell, K. \& Davis, D., 2011, 'Sustainability and triple bottom line reporting. What is it all about?', International Journal of Business, Humanities and Technology 1(1), 55-59.

Archel, P., Fernandez, M. \& Larrinaga, C., 2008, 'The organizational and operational boundaries of triple bottom line reporting: A survey', Environmental Management 41(2), 106-117. https://doi.org/10.1007/s00267-007-9029-7, PMid:17990022.

Berger, I., Cunningham, P. \& Drumwright, M., 2007, 'Mainstreaming corporate socia responsibility: Developing markets for virtue', California Management Review 49(2), 132-157. https://doi.org/10.2307/41166409

Brundtland, G.H., 1987, 'Our common future - Call for action', Environmental Conservation 14(4), 291-294. https://doi.org/10.1017/\$0376892900016805

Casanova, L., 2010, 'Corporate social responsibility and Latin American multinationals: Is poverty a business issue?', Universia Business Review 2(2), 132-145.

Clark, V.L., 2010, 'The adoption and practice of mixed methods: U.S. trends in federally funded health-related research', Qualitative Inquiry 16(2), 428-440. https://doi. org/10.1177/1077800410364609

De Ridder, W., 2007, 'A framework for tool selection and use in integrated assessment for sustainable development', Journal of Environmental Assessment Policy and Management 9(4), 423-441. https://doi.org/10.1142/S1464333207002883

Dutta, S., 2011, 'Triple bottom line reporting: An innovative accounting initiative', International Journal on Business, Strategy and Management 1(1), 1-13.

Dutta, S., 2012, 'Triple bottom line reporting: An Indian perspective', Interdisciplinary Journal of Contemporary Research in Business 3(12), 652-659.

Ekwueme, C.M., Egbunike, C.F. \& Onyali, C.I., 2013, 'Benefits of triple bottom line disclosures on corporate performance: An exploratory study of corporate stakeholders', Journal of Management and Sustainability 3(2), 212-254. https:// doi.org/10.5539/jms.v3n2p79

Etzion, D. \& Ferraro, F., 2009, 'The role of analogy in the institutionalization of sustainability reporting', Organization Science 21(2), 109-117.
Fauzi, H., Svensson, G. \& Rahman, A., 2010, "Triple bottom line" as "Sustainable corporate performance": A proposition for the future', Sustainability 2(5), 145-160. https://doi.org/10.3390/su2051345

Fell, N., 2008, Triple bottom line approach growing in non-profit sector, Doubleday, New York.

Galamadien, P.A., 2011, 'Sustainability and triple bottom line reporting in the banking industry', mini-dissertation submitted in partial fulfilment of the requirements for the degree Master in Business Administration at the Potchefstroom campus of the North-West University.

Gordon, L.W. \& Reddy, K., 2010, 'The effect of sustainability reporting on financial performance: An empirical study using listed companies', Journal of Asia Entrepreneurship and Sustainability 6(2), 19-42.

Hacking, T. \& Guthrie, P., 2008, 'A framework for clarifying the meaning of triple bottom-line, integrated, and sustainability assessment', Environmental Impact Assessment Review 28(3), 73-89. https://doi.org/10.1016/j.eiar.2007.03.002

Harrison, J.S. \& Wicks, A.C., 2013, 'Stakeholder theory, value, and firm performance', Business Ethics Quarterly 23(1), 97-124. https://doi.org/10.5840/beq20132314, PMid:18174597, PMCid:PMC2174757.

Hewitt, C., Mitchell, N. \& Torgerson, D., 2008, 'Listen to the data when results are not significant', British Medical Journal 33(6), 23-25. https://doi.org/10.1136/ bmj.39379.359560.AD

Ho, L.C. \& Taylor, M., 2007, 'An empirical analysis of triple bottom-line reporting and its determinants: Evidence from the United States and Japan', Journal of International Financial Management and Accounting 18(2), 123-150. https://doi. org/10.1111/j.1467-646X.2007.01010.x

Hubbard, G., 2009, 'Measuring the organisational performance: Beyond the triple bottom-line', Business Strategy and the Environment 18(1), 177-191. https://doi. org $/ 10.1002 /$ bse. 564

Michigan City, 2008, Community triple bottom line indicator report, Michigan City of Grand Rapids, MI.

Mish, J. \& Scammon, D.L., 2010, 'Principle-based stakeholder marketing: Insights from private triple bottom-line firms', Journal of Public Policy \& Marketing 29(1), 12-26. https://doi.org/10.1509/jppm.29.1.12

Mitchell, M., Curtis, A. \& Davidson, P., 2008, 'Evaluating the process of triple bottom line reporting: Increasing the potential for change', Local Environment 13(2), 67-80. https://doi.org/10.1080/13549830701581937

Morse, J.M., 2010, 'Simultaneous and sequential qualitative mixed method designs', Qualitative Inquiry 16(2), 483-491. https://doi.org/10.1177/1077800410364741

Niehaus, G., 2016, Investigating the current supply chain sustainability reporting practices of South African Organisations, University of Pretoria, Pretoria.

Raushan, G., 2015, 'Measuring organizational performance: A new approach to triple bottom line reporting and stakeholder engagement', British Journal of Business and Management Research 2(1), 69-80.

Seda, 2016, The small, medium and micro enterprise sector of South Africa, Bureau of Economic Research, Cape Town.

Schulz, S.A. \& Flanigan, R.L., 2016, 'Developing competitive advantage using the triple bottom line: A conceptual framework', Journal of Business \& Industrial Marketing 31(4), 449-458. https://doi.org/10.1108/JBIM-08-2014-0150

Shezi, M., 2013, SMEs' Corporate Governance Systems: Status and effects on sustainability, University of Pretoria, Pretoria. PMid:23892950.

Skouloudis, A., Evangelinos, K. \& Kourmousis, F., 2009, 'Development of an evaluation methodology for triple bottom line reports using international standards on reporting', Environmental Management 4(4), 298-311. https://doi.org/10.1007/ s00267-009-9305-9, PMid:19495861.

Slaper, T.F. \& Hall, T.J., 2011, 'The triple bottom line: What is it and how does it work?', Indiana Business Review 86(1), 4-8.

Spicer, D., 2013, SA business still coming to terms with triple-bottom-line reporting Engineering News, Johannesburg.

Stephen, R.J.S. \& Meitner, M., 2007, 'Using multi-criteria analysis and visualization for sustainable forest management planning with stakeholder groups', Forest, Ecology and Management 207(2), 171-187.

Suttipun, M., 2012, 'Triple bottom line reporting in annual reports: A case study of companies listed on the Stock Exchange of Thailand (SET)', Asian Journal of Finance \& Accounting 4(1), 12-89. https://doi.org/10.5296/ajfa.v4i1.1289

Tran, T., 2015, Corporate social responsibility and profits: A tradeoff or a balance? Stanford University, Standford.

Tyrrell, T., Paris, C.M. \& Biaett, V., 2013, 'A quantified triple bottom line for tourism experimental results', Journal of Travel Research 52(3), 279-293. https://doi. org/10.1177/0047287512465963

Wang, L. \& Lin, L., 2007, 'A methodology framework for the triple bottom line accounting and management of industry enterprises', International Journal of Production Research 45(5), 106-188. https://doi.org/10.1080/00207540600635136 